\title{
Meta-analysis of randomized trials on access site selection for percutaneous coronary intervention in ST-segment elevation myocardial infarction
}

\author{
András Komócsi ${ }^{1}$, Dániel Aradi ${ }^{1}$, Dániel Kehl ${ }^{2}$, Imre Ungi ${ }^{3}$, Attila Thury ${ }^{3}$, Tünde Pintér ${ }^{1}$,
} James J. Di Nicolantonio ${ }^{4}$, Adrienn Tornyos ${ }^{1}$, András Vorobcsuk ${ }^{1}$

\author{
${ }^{1}$ Heart Institute, University of Pécs, Hungary \\ ${ }^{2}$ Department of Statistics and Econometrics, Faculty of Business and Economics, \\ University of Pécs, Hungary \\ ${ }^{3}$ Invasive Cardiology Unit, Cardiology Center, University of Szeged, Hungary \\ ${ }^{4}$ Wegmans Pharmacy, Ithaca, New York, USA
}

Submitted: 6 April 2013

Accepted: 4 June 2013

Arch Med Sci 2014; 10, 2: 203-212

DOI: 10.5114 /aoms.2014.42570

Copyright (C) 2014 Termedia \& Banach

\begin{abstract}
Introduction: Superior outcomes with transradial (TRPCI) versus transfemoral coronary intervention (TFPCI) in the setting of acute ST-segment elevation myocardial infarction (STEMI) have been suggested by earlier studies. However, this effect was not evident in randomized controlled trials (RCTs), suggesting a possible allocation bias in observational studies. Since important studies with heterogeneous results regarding mortality have been published recently, we aimed to perform an updated review and meta-analysis on the safety and efficacy of TRPCI compared to TFPCI in the setting of STEMI. Material and methods: Electronic databases were searched for relevant studies from January 1993 to November 2012. Outcome parameters of RCTs were pooled with the DerSimonian-Laird random-effects model.

Results: Twelve RCTs involving 5,124 patients were identified. According to the pooled analysis, TRPCI was associated with a significant reduction in major bleeding (odds ratio (OR): 0.52 (95\% confidence interval $(\mathrm{Cl})$ 0.38-0.71, $p<0.0001)$ ). The risk of mortality and major adverse events was significantly lower after TRPCI (OR $=0.58(95 \% \mathrm{Cl}: 0.43-0.79), p=0.0005$ and $\mathrm{OR}=0.67$ (95\% Cl: 0.52-0.86), $p=0.002$ respectively).

Conclusions: Robust data from randomized clinical studies indicate that $\mathrm{TRPCl}$ reduces both ischemic and bleeding complications in STEMI. These findings support the preferential use of radial access for primary $\mathrm{PCl}$.
\end{abstract}

Key words: ST-segment elevation myocardial infarction, transradial, transfemoral, death.

\section{Introduction}

Serious bleeding events are considered major contributors to higher morbidity and mortality in patients undergoing percutaneous coronary intervention $(\mathrm{PCl})$ [1]. Therefore, in the current era of potent antithrombotic regimens, preventing bleeding after $\mathrm{PCl}$ remains a major goal. The transradial approach (TRPCI) to coronary interventions has the potential advantage of reducing access site bleeding complications compared to

\author{
Corresponding author: \\ András Vorobcsuk MD, PhD \\ Heart Institute \\ University of Pécs \\ 13. Ifjúság $u$. \\ H-7624 Pécs, Hungary \\ Phone: (36) 72536 001/5660 \\ Fax: (36) 72536387 \\ E-mail: vorobcsukandras@ \\ gmail.com
}


transfemoral intervention (TFPCI) [2]. However, the exact role of the transradial approach is still debated by the interventional cardiology community $[3,4]$. Radialists emphasize the importance of reducing access site bleeding complications together with early ambulation and discharge, which result in better patient comfort [5]. Opponents argue for longer procedural times, higher risk of crossover to femoral puncture, and higher radiation exposure due to the capricious radial anatomy that might compromise timely reperfusion [6].

Numerous studies and meta-analyses have been carried out to compare the safety of the two approaches. As a conclusion, the radial approach was found to reduce major bleeding complications $[2,5]$. Furthermore, a prior meta-analysis including the high-risk subset of patients with ST-segment elevation myocardial infarction (STEMI) demonstrated a reduction in ischemic events in the case of TRPCI and a significant mortality benefit [7]. These effects were, however, not consistent in the observational studies and randomized controlled trials (RCTs), i.e. the reduction of neither bleeding nor ischemic events reached the level of significance in RCTs, which may be explained by a possible allocation bias in observational studies (OSs). Lately, meta-analyses including trials with random allocation and focusing on the STEMI subset have reported significant reduction in patient-oriented end-points as well as mortality [8-11]. Recently, large-scale, well-designed studies have been published but their results were not unambiguously positive regarding mortality.

Our objective was to perform an updated review and meta-analysis on the safety and efficacy of TRPCI vs. TFPCI in the setting of STEMI.

\section{Material and methods}

\section{Search strategy}

The analyses were performed according to the PRISMA guideline [12]. Electronic databases were searched for relevant studies between January 1993 and February 2013. Relevant publications were identified from MEDLINE ${ }^{\circledR}$, SCOPUS ${ }^{\oplus}$, the Web of Science ${ }^{\circledast}$ with Conference Proceedings, and the Cochrane Central Register of Controlled trials (CENTRAL) using a search strategy that combined text word and MeSH headings. Search keywords included various combinations of the following terms: "transradial", "transfemoral", "radial access", "STEMl”, "myocardial”, "infarct"”. Furthermore, we augmented the search with the reference lists of the relevant studies and reviews, editorials, letters, and also relevant abstracts and presentations from the annual meetings of the American Heart Association, the American College of Cardiology, the European Society of Cardiology and Transcatheter Cardiovascular Therapeutics. No language restriction was used.

\section{Selection criteria}

We selected all randomized trials that evaluated the clinical impact of TRPCI vs. TFPCI in STEMI. The following clinical outcomes with the longest follow-up available were selected: (a) overall mortality (b) major adverse cardiovascular and cerebrovascular events (MACE), including death, recurrent myocardial infarction, emergency percutaneous coronary intervention $(\mathrm{PCl})$ or coronary artery bypass graft surgery (CABG), and stroke according to the definitions used in the trials; (c) and major bleeding. A standardized major bleeding definition adapted from the meta-analysis of Jolly et al. was used [5]. Briefly, major bleeding was defined as one of the following: fatal bleeding, intracranial hemorrhage, or bleeding associated with $a \geq 3 \mathrm{~g} / \mathrm{dl}$ hemoglobin drop or requiring transfusion or requiring surgery (pseudoaneurysms requiring thrombin injection or ultrasound compression were excluded). For trials where the composite definition was not available, either transfusion rates or proportion of bleeding events associated with $\mathrm{a} \geq 3 \mathrm{~g} / \mathrm{dl}$ hemoglobin drop were substituted for major bleeding).

Secondary procedural outcomes were: procedural time (in minutes), door-to-reperfusion time (in minutes), fluoroscopy time (in minutes), volume of contrast agent $(\mathrm{ml})$, length of hospital stay (in days), and access site crossover.

Selection and data abstraction were done independently by two reviewers on pre-specified structure collection forms. Disagreements were resolved by consensus and discussion with a third party.

\section{Statistical analysis}

Statistical analysis was performed using the Open Meta-Analyst software, version 4.16.12, Tufts University, http://tuftscaes.org/open_meta/. Odds ratio $(\mathrm{OR})$ was calculated from the event frequencies and pooled with the DerSimonian-Laird random-effects model. Continuous variables were compared with the inverse-variance method. The choice of random-effects model was made based on the consideration that the true effect of access site choice may vary from study to study influenced by heterogeneity of the included trials. The random-effects model accounts better for inter-study differences. Furthermore, it results in wider confidence intervals and thus provides more conservative and robust results. Heterogeneity was assessed with a $\chi^{2}$ heterogeneity statistic and an $R^{2}$ statistic [13]. Sensitivity and subgroup analyses were performed using the following categories: 
single center or multicenter trials, trials with patient number over or less than 200, in extenso published trials, primary $\mathrm{PCl}$ and rescue $\mathrm{PCl}$ (studies with $>50 \%$ of the patients undergoing $\mathrm{PCl}$ were included in this group), cohorts whose use of GP $\mathrm{Ilb} / \mathrm{lll}$ a inhibitor was below and over $40 \%$. To study the relevance of publication bias, funnel plots were constructed plotting the trial results against their precision. Egger's regression intercept was used to assess the asymmetry of the funnel plots.

\section{Results}

\section{Search results and study selection}

Our search resulted in 904 citations. After the evaluation of abstracts, 33 potentially appropriate studies were found. Finally, 12 studies were selected for data extraction and analysis (Figure 1). These articles included 10 RCTs involving published in extenso articles [14-23]. One study [24] was published only as abstract, but this was included in the analysis because of the importance of the so-called "gray" literature and because the data required for our analysis were available either from the abstract or from additional online sources (www.cardiosource.org). The included trials involved 5,124 patients. Detailed characteristics are summarized in Tables I-II.

\section{Clinical results}

Based on the pooled results of the random-effects model meta-analysis, TRPCI was associated with a $48 \%$ odds reduction in major bleeding events compared to TFPCI (OR = 0.52 (95\% Cl: 0.38-071), $p<0.0001$ ) (Figure 2). A $42 \%$ odds reduction for mortality and $33 \%$ odds reduction for MACE were also observed favoring the transradial approach $(\mathrm{OR}=0.58(95 \% \mathrm{Cl}: 0.43-0.79), p=0.0005$, and 0.67 (95\% Cl: 0.52-0.86), $p=0.002$, respectively). These effects were homogeneous among the included trials (Figures 3 and 4).

Transradial intervention was associated with shorter hospital stay (mean: 6.84 days vs. 8.58 days; mean difference (MD): -1.74 days $(95 \% \mathrm{Cl}$ : $-2.91,-0.56), p=0.004$ ) but with higher frequency of access site crossover (OR $=3.68$ (95\% Cl: 2.54 , 5.32), $p<0.00001)$ and longer time to reperfusion (MD $3.28 \min (95 \% \mathrm{Cl}: 1.02,5.54), p=0.005)$. There were no significant differences in procedural (mean: $47.9 \mathrm{~min}$ vs. $46.6 \mathrm{~min}$ ), fluoroscopy times (mean: $11.0 \mathrm{~min}$ vs. $10.3 \mathrm{~min}$ ) and in the used contrast volume (mean: $169 \mathrm{ml}$ vs. $166 \mathrm{ml}$ ). Occurrence of any vascular complication was lower after transradial intervention $(\mathrm{OR}=0.50(95 \% \mathrm{Cl}$ : $0.36,0.71), p<0.0001)$. The access site bleeding complications were lower in case of the transradial approach $(\mathrm{OR}=0.39(95 \% \mathrm{Cl}: 0.22,0.69)$, $p=0.001)$. Stratification and sensitivity analyses

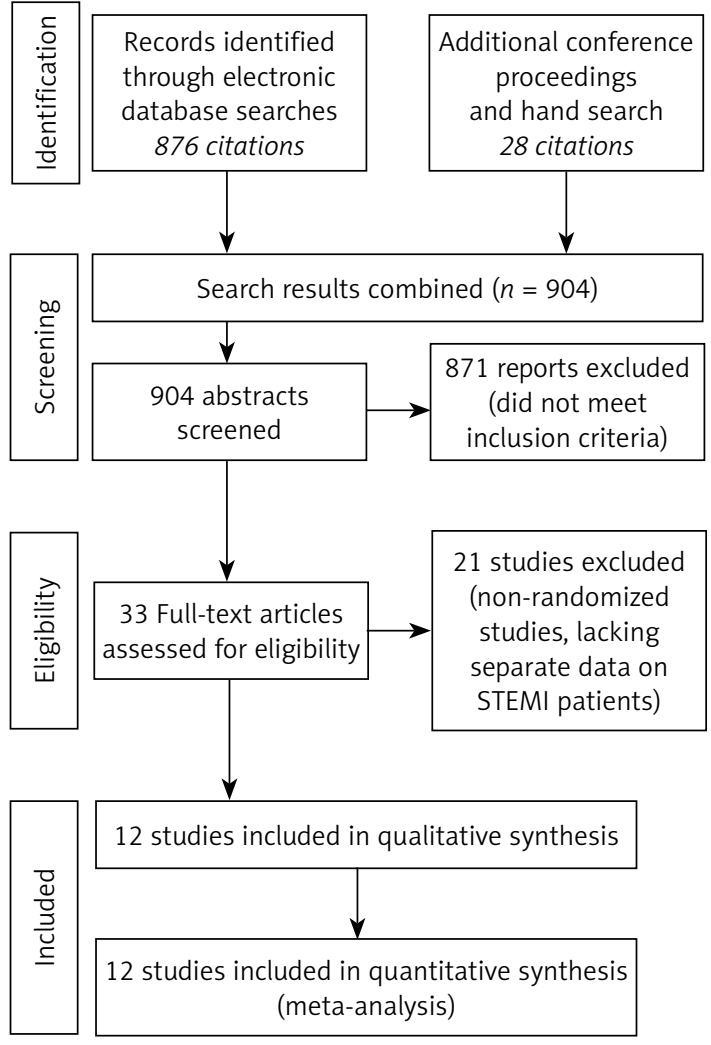

Figure 1. Flowchart of trials

showed results similar to those of the comprehensive analysis. Findings were also comparable after pre-specified stratification in studies involving high-risk patients (i.e. studies that included patients with preceding thrombolysis, and with $>45 \%$ use of GP IIb/IIla inhibitors) study size, single or multicenter design or means of publication (Table III). Analyses for publication bias did not show skewed distribution (Figure 5).

\section{Discussion}

The current analysis with the latest available evidence confirms the preferential use of the transradial approach in patients with acute myocardial infarction. The TRPCI reduced the risk of mortality, major adverse cardiac events and bleeding complications compared to the historical standard femoral approach.

Intriguingly, the application of the transradial approach for coronary intervention shows considerable geographical differences, and its adoption is limited by concerns about longer procedural times, higher radiation exposure and more frequent access site crossover [25]. Although numerous data support that these disadvantages are mostly related to the learning curve period and can be easily tackled thereafter, these aspects have questioned the possible benefits of TRPCI in clinical settings where timely reperfusion is crucial [26]. 


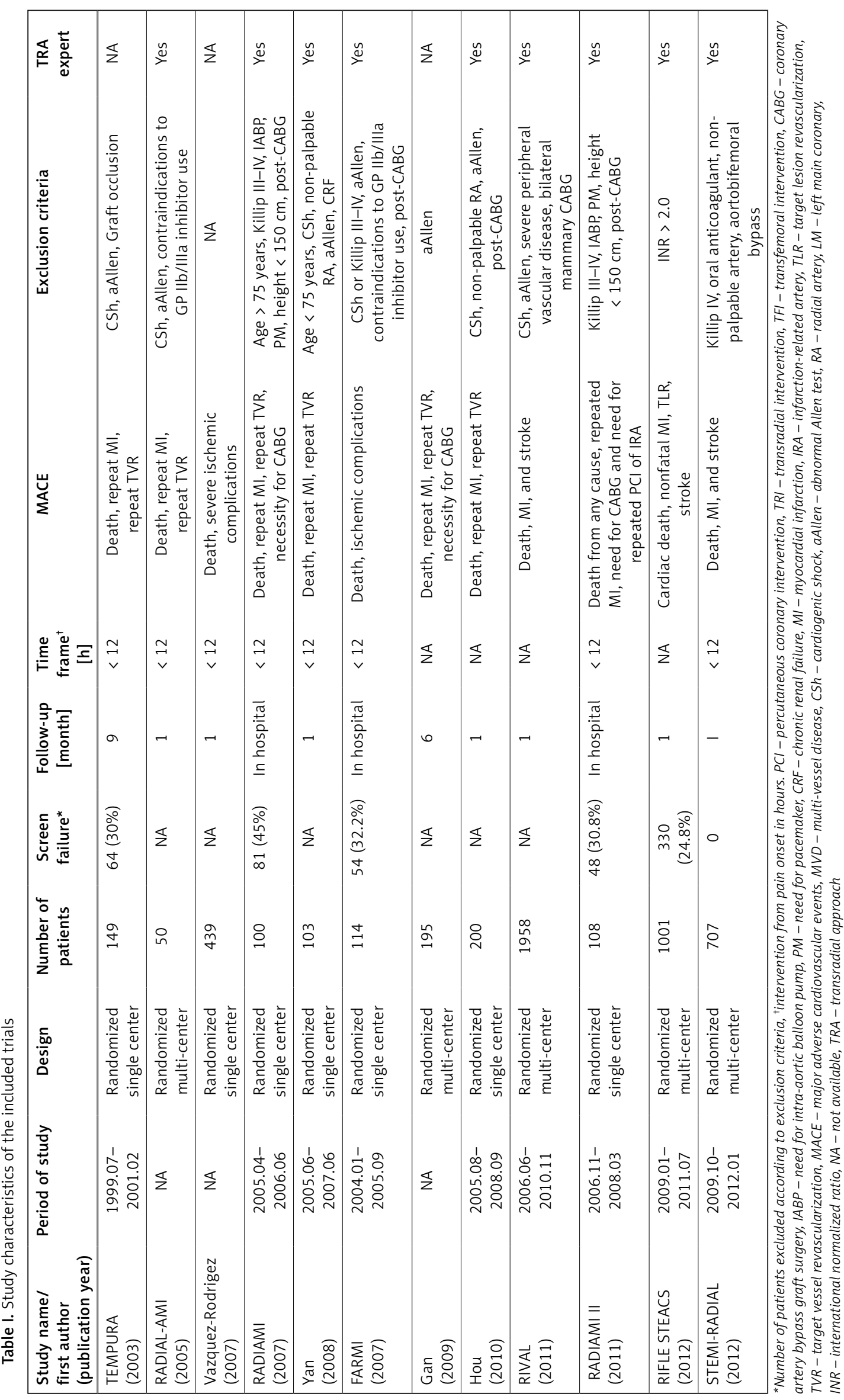




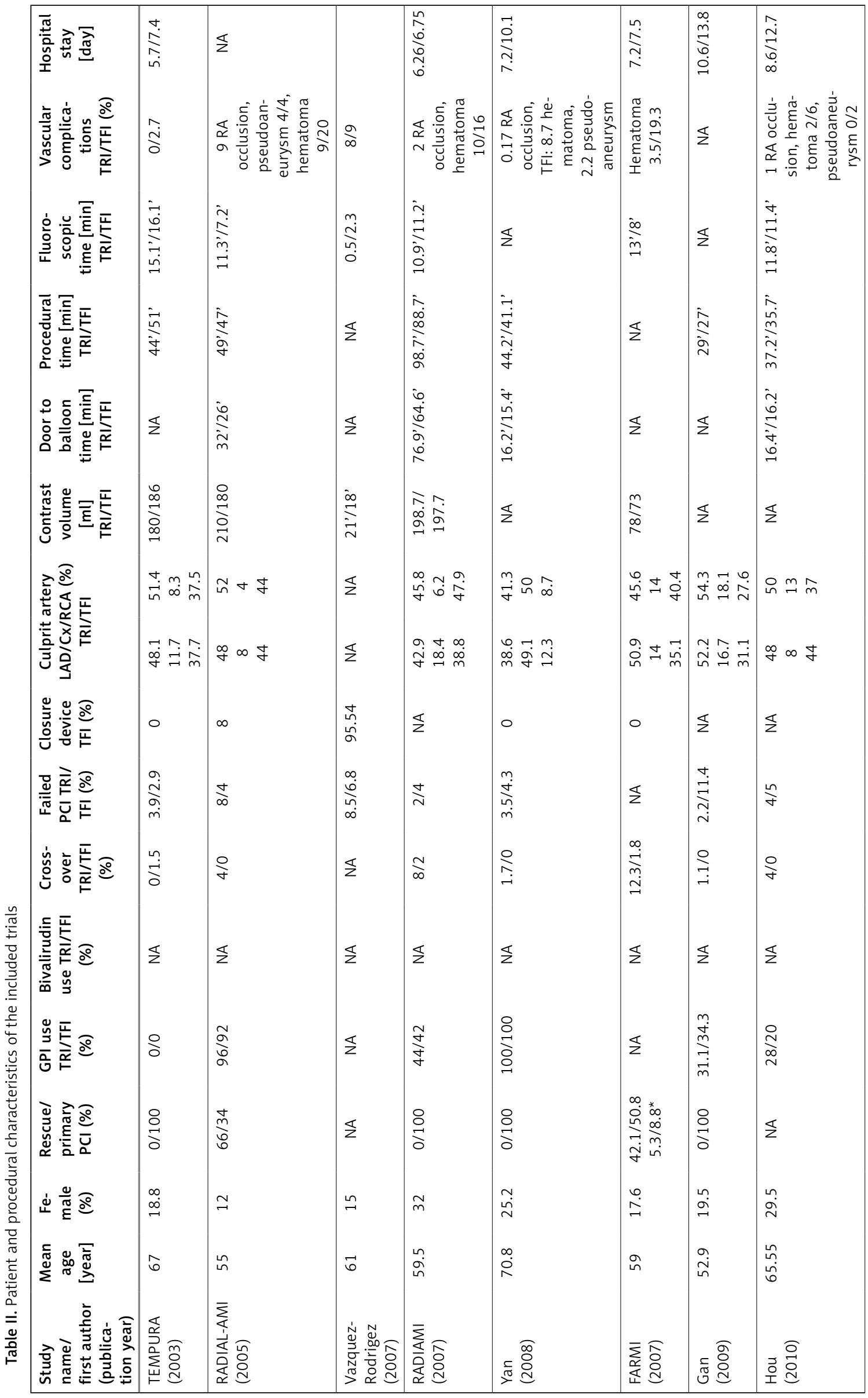




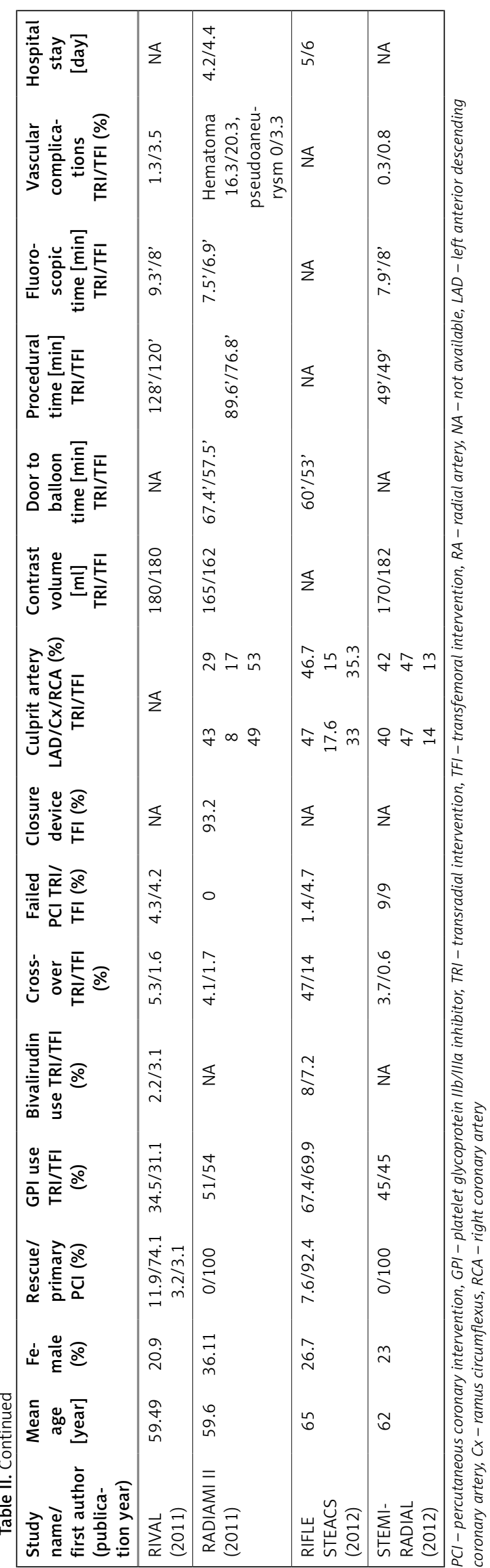

Two prior meta-analyses that pooled data from randomized trials and compared transradial and transfemoral $\mathrm{PCl}$ regardless of the clinical setting found that TRPCI was a safer alternative that reduced access site bleeding complications. However, no difference was found either in terms of major ischemic outcomes or in mortality [2,5]. These works shared a common limitation as they included trials with low risk populations that may explain these latter findings. In addition to this, in the analysis of Agostoni et al., the low number of events and the use of 'access site complication' as an end-point (that incorporated a wide range of events with different clinical relevance) made the results difficult to interpret clinically [2]. In their meta-analysis Jolly et al. classified bleeding events as relevant endpoints and reported a significant reduction in bleeding; however, it failed to confirm a significant benefit regarding ischemic events [5]. Lately, in an analysis of 76 studies (15 randomized, 61 observational) involving a total of 761,919 patients Bertrand et al. found no significant benefit of mortality or of the composite of death and MI in randomized trials [27].

The above results conflicted with the findings of a pooled analysis including 32,822 patients from three prospective registries in British Columbia, where TRPCI was found to reduce transfusion rates by $50 \%$, which translated into reduced short- and long-term mortality [28]. Of note, the link between transfusion and mortality suggested by this registry data was not further supported by the RIVAL trial. In this, so far the largest acute coronary syndrome trial, significant benefit of the transradial approach was demonstrated among STEMI patients but not among non-STE ACS cases, while the rates of transfusion showed no differences (1.16\% vs. $1.51 \%$ and 3.46 vs. 3.31, $p=0.493$ and 0.765 , respectively) [29].

The clinical setting with the inherently different bleeding and ischemic risks of patients may have a substantial influence on the benefits of the transradial approach. The feasibility and possible benefits of TRPCI in acute coronary syndromes were very early reported by Japanese authors [14]. Similarly to the positive registry data, our earlier meta-analysis confirmed that besides reducing bleeding, TRPCI was also associated with a lower risk for thrombotic events and mortality in patients with STEMI [7]. The limitation of this latter analysis was that the observed benefit was not significant in the sensitivity analysis that included only randomized, controlled trials. Although the estimates suggested lack of statistical power as an explanation, a selection bias in observational studies influencing access site preference in different patients could not be excluded.

Influence of the clinical setting is further supported by the analysis the "Trans-radial Versus Trans-femoral Percutaneous Coronary Intervention (PCI) Access Site Approach in Patients With Un 


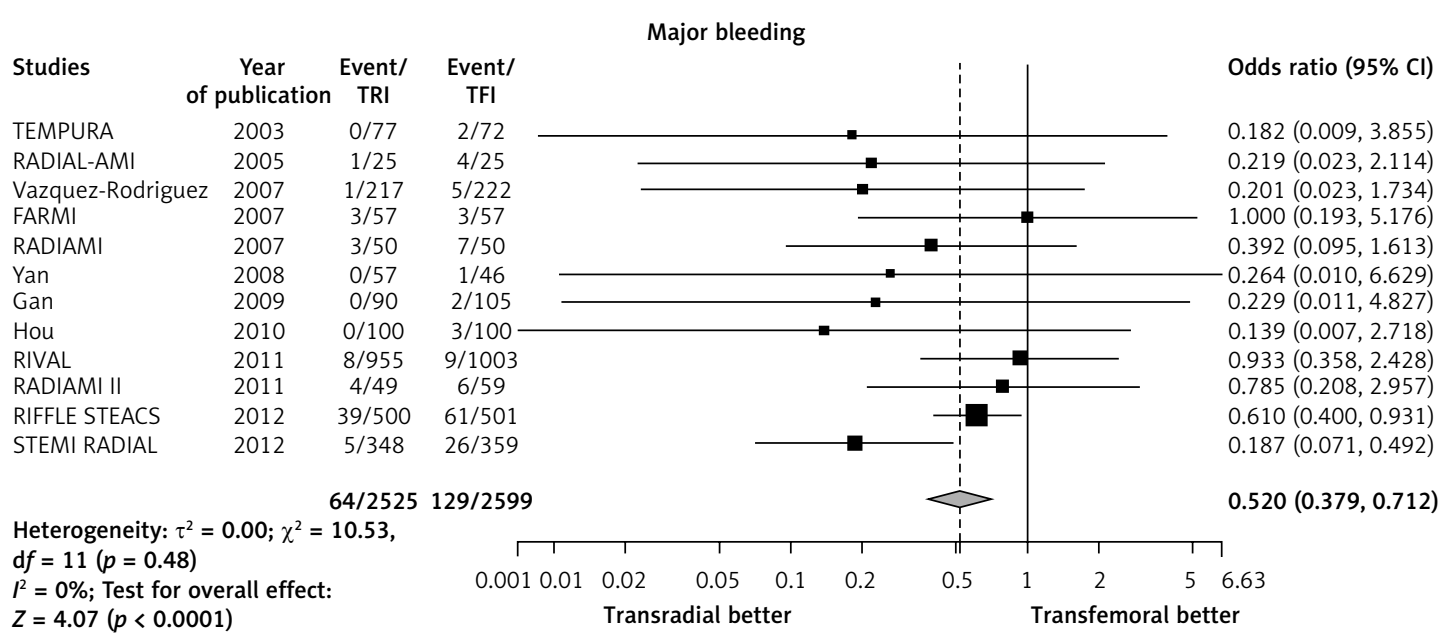

Figure 2. Risk of major bleeding

$\mathrm{Cl}$ - confidence interval, TRI - transradial intervention, TFI - transfemoral intervention

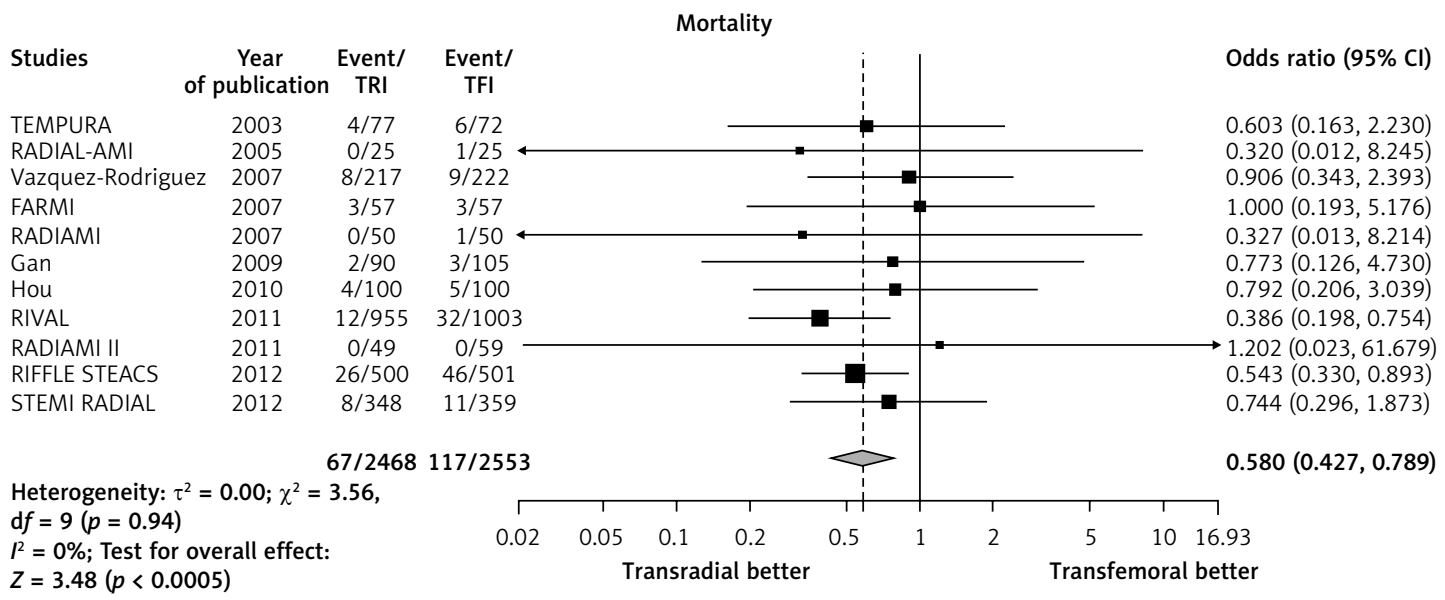

Figure 3. Risk of death

$\mathrm{Cl}$ - confidence interval, TRI - transradial intervention, TFI - transfemoral intervention

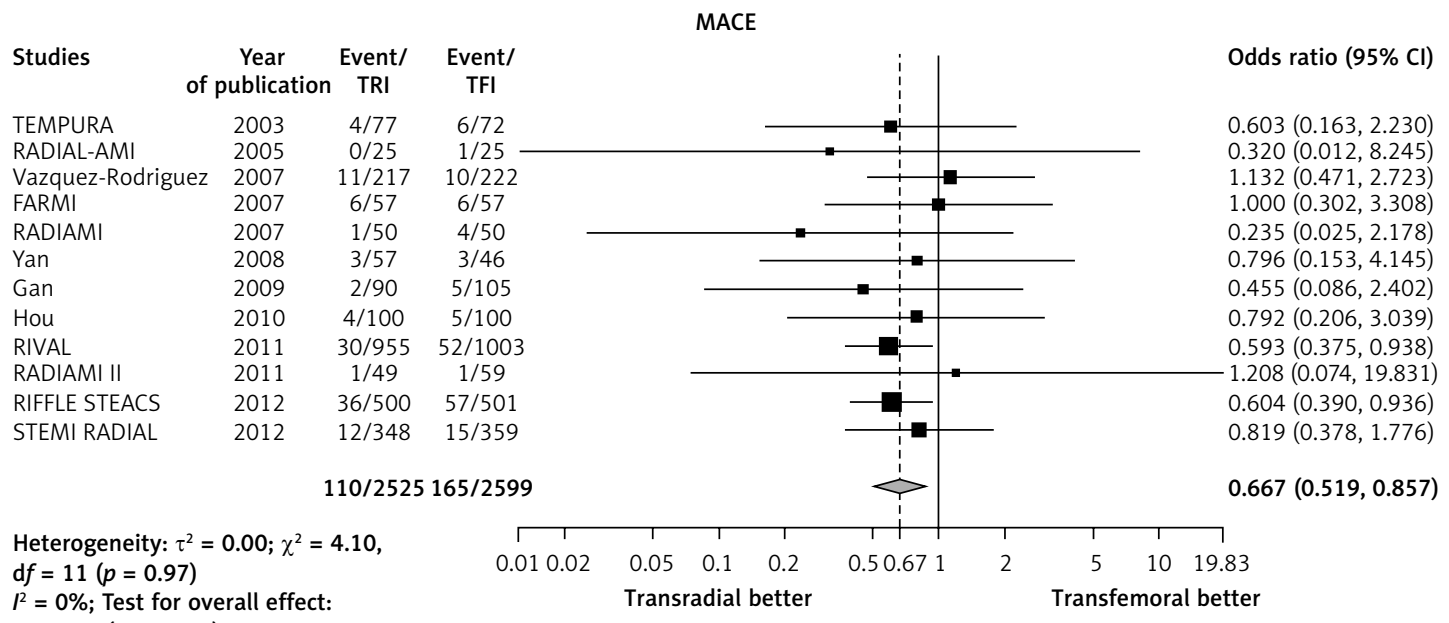

$R^{2}=0 \%$; Test for overall effect:

$Z=3.17(p<0.002)$

Figure 4. Risk of major adverse events (MACE)

$\mathrm{Cl}$ - confidence interval, TRI - transradial intervention, TFI - transfemoral intervention 
Table III. Sensitivity and subgroup analyses

\begin{tabular}{|c|c|c|c|c|c|}
\hline \multicolumn{2}{|c|}{ Subgroup analysis } & $\begin{array}{l}\text { Number } \\
\text { of studies } \\
\text { (number of } \\
\text { patients) }\end{array}$ & \multicolumn{3}{|c|}{ Odds ratio $(95 \% \mathrm{Cl})$} \\
\hline Overall effect & $\begin{array}{c}\text { Fixed effect } \\
\text { model }\end{array}$ & $12(5124)$ & $0.66(0.52,0.85)^{\star \star *}$ & $0.57(0.42,0.78)^{\star \star \star *}$ & $0.49(0.36,0.66)^{\star * *}$ \\
\hline \multirow[t]{2}{*}{ Publication } & In extenso & $10(3978)$ & $0.62(0.47,0.81)^{* * *}$ & $0.53(0.37,0.75)^{\star * *}$ & $0.59(0.42,0.82)^{* *}$ \\
\hline & $\begin{array}{l}\text { Abstract or } \\
\text { conference }\end{array}$ & $2(1146)$ & $0.94(0.53,1.69)$ & $0.82(0.42,1.60)$ & $0.19(0.08,0.46)^{\star * *}$ \\
\hline \multirow[t]{2}{*}{ Design } & Single center & $7(1213)$ & $0.85(0.51,1.42)$ & $0.79(0.43,1.45)$ & $0.43(0.22,0.86)^{*}$ \\
\hline & Multi-center & $5(3911)$ & $0.62(0.46,0.82)^{\star \star \star}$ & $0.52(0.36,0.74)^{\star \star \star}$ & $0.50(0.36,0.71)^{\star \star *}$ \\
\hline \multirow{2}{*}{$\begin{array}{l}\text { Number of } \\
\text { patients }\end{array}$} & $<200$ & $7(819)$ & $0.65(0.34,1.24)$ & $0.67(0.29,1.53)$ & $0.47(0.23,0.94)^{*}$ \\
\hline & $\geq 200$ & $5(4305)$ & $0.67(0.51,0.88)^{\star \star}$ & $0.56(0.41,0.79)^{\star * *}$ & $0.49(0.35,0.69)^{\star * *}$ \\
\hline \multirow[t]{2}{*}{ Rescue PCl } & Yes & $4(3123)$ & $0.62(0.45,0.83)^{\star \star}$ & $0.50(0.34,0.73)^{\star \star *}$ & $0.64(0.45,0.93)^{*}$ \\
\hline & No & $6(1362)$ & $0.68(0.39,1.18)$ & $0.68(0.34,1.35)$ & $0.29(0.16,0.54)^{\star \star \star}$ \\
\hline \multirow{2}{*}{$\begin{array}{l}\text { GP IIb/IIIa } \\
\text { use }\end{array}$} & $<45 \%$ & $5(2602)$ & $0.58(0.39,0.86)^{\star *}$ & $0.48(0.29,0.81)^{* \star}$ & $0.52(0.26,1.03)^{*}$ \\
\hline & $\geq 45 \%$ & $5(1969)$ & $0.66(0.46,0.95)^{*}$ & $0.58(0.37,0.89)^{\star *}$ & $0.19(0.08,0.46)^{\star \star *}$ \\
\hline
\end{tabular}

${ }^{*} p<0.05,{ }^{* *} p \leq 0.01,{ }^{* *} p \leq 0.001$. MACE - major adverse cardiovascular events

A

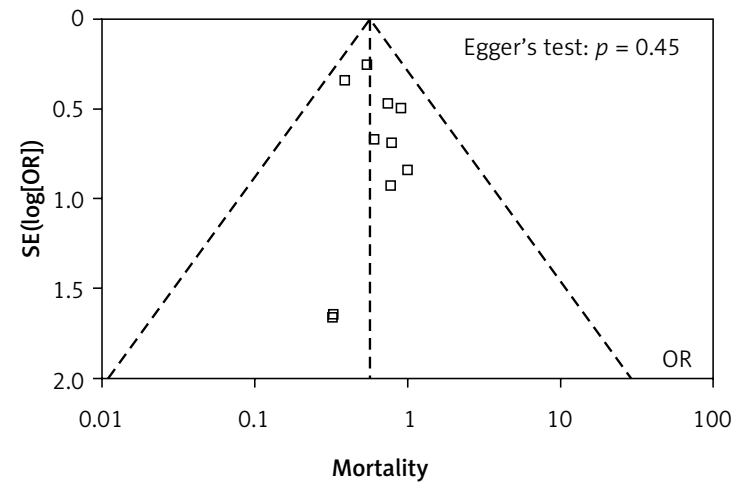

B

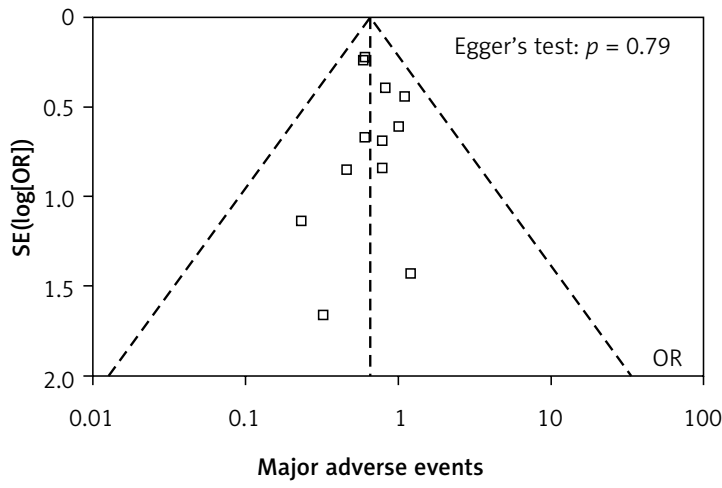

Figure 5. Funnel plots for visualizing potential publication bias. A - A funnel plot for overall mortality. B - The plot for major adverse events. No skewed distribution could be observed

stable Angina or Myocardial Infarction Managed With an Invasive Strategy" (RIVAL) trial, which was a randomized, parallel group, multicenter study involving 7021 patients with acute coronary syndromes. In patients with STEMI, a significant, $40 \%$ relative reduction in the primary endpoint was observed, together with a $61 \%$ relative decrease in mortality, although the results of the overall trial did not show a significant benefit for TRPCI over TFPCI in the primary endpoint $[21,30]$. Meta-analyses including data of the STEMI subgroup of this trial found that the benefit of TRPCI regarding major composite events and mortality became significant [8-11]. However, the main restriction of these analyses is that they were dominated by data from the RIVAL trial representing approximately $60 \%$ of the weight attributed to the randomized trials, and sensitivity analyses by the exclusion of the RIVAL data still showed insignificant benefit [8].
Two important multicentre RCTs have been published on this topic. The "Radial Versus Femoral Investigation in ST Elevation Acute Coronary Syndrome" (RIFLE STEACS) trial randomized 1001 patients in four high-volume centers. This study showed a significant reduction in major adverse cardiac events and in 30-day mortality [22]. The STEMI-RADIAL trial of similar design randomized 707 STEMI patients and found an $80 \%$ decrease in bleeding events. Intriguingly, the TRPCI did not influence the frequency of MACE or mortality significantly $(4.2 \%$ vs. $3.5 \%, p=0.7$ and $3.1 \%$ vs. $2.3 \%$, $p=0.4$, respectively) [24].

Based on these results, we aimed to reanalyze the safety and efficacy of TRPCI and found that the upto-date evidence from randomized trials convincingly supports the current recommendations advising the use of the radial approach in STEMI cases [31].

Our meta-analysis has a number of potential limitations. Study-level meta-analyses are consid- 
ered as less conclusive than data from adequately powered clinical trials. Based on the effect estimates from our analysis, a sample size of 2000 in each group would result a $95 \%$ power to detect a decrease of 0.02 in mortality with a significance level of 0.05 (two-tailed). Consequently, the trials performed so far were possibly underpowered, which validates the use of meta-analysis in order to achieve greater statistical power and more precise effect estimates. Furthermore, we may anticipate that none of the currently registered trials will substantially change this situation. (MATRIX NCT01433627 (estimated enrollment: 6800, proportion of STEMI cases: unknown), SAFARI-STEMI NCT01398254 (estimated enrollment: 1274, proportion of STEMI cases: $100 \%)$ ).

Although our findings provide a robust support for TRPCI in STEMI in terms of efficacy, data regarding the occurrence of vascular complications were strikingly inconsistent. We pooled the data according to reported occurrence of any vascular complications and of access site bleeding and found benefit in both measures. However, besides lack of uniform reporting the results of these analyses should be cautiously interpreted as vascular complications have different clinical relevance related to their anatomical situations. This may result in observational, assessment, and referral bias.

An inherent limitation of any meta-analysis is that of publication bias. Therefore we extended our search to non-English and abstract publications. Consequently, the included trials show a wide range in size and origin and many of these were small trials with limited ability to assess clinical outcomes individually. However, subgroup analysis according to the means of publication and trial size showed no meaningful differences while our analysis for publication bias did not demonstrate the presence of this potential confounder. Furthermore, there were differences in medication and in operator experience across the trials. Because the trials in our meta-analysis were randomized, the effect of these limitations should be minimized. Appropriate training in transradial intervention, however, is of high importance and we believe that our findings regarding access site selection are applicable for experienced transradial operators.

Our updated meta-analysis demonstrates that the transradial access reduces mortality, MACE and the rate of bleeding events compared to the transfemoral access. The low heterogeneity of the outcome data also corroborates the robustness of these findings. Hospital stay was also shorter in patients with transradial intervention, but these benefits were accompanied by higher frequency of access site crossover and longer time to reperfusion. Data regarding procedural time param- eters and contrast use were heterogeneous but not significantly different. Overall, it seems that possible technical drawbacks do not compromise the clinical efficacy of the transradial intervention. Therefore, transradial PCI should be favored over TFPCI in patients with STEMI.

In conclusion, robust data from randomized clinical studies indicate that TRPCI reduces both ischemic and bleeding complications in STEMI. These findings support the preferential use of radial access for primary $\mathrm{PCl}$.

\section{Reference}

1. Eikelboom JW, Mehta SR, Anand SS, Xie C, Fox KA, YusufS. Adverse impact of bleeding on prognosis in patients with acute coronary syndromes. Circulation 2006; 114: 774-82.

2. Agostoni P, Biondi-Zoccai GG, de Benedictis ML, et al. Radial versus femoral approach for percutaneous coronary diagnostic and interventional procedures; Systematic overview and meta-analysis of randomized trials. J Am Coll Cardiol 2004; 44: 349-56.

3. Louvard Y, Kumar S, Lefevre T. Percentage of transradial approach for interventional cardiology in the world and learning the technique. Ann Cardiol Angeiol (Paris) 2009; 58: 327-32.

4. Rao SV, Ou FS, Wang TY, et al. Trends in the prevalence and outcomes of radial and femoral approaches to percutaneous coronary intervention: a report from the National Cardiovascular Data Registry. JACC Cardiovasc Interv 2008; 1: 379-86.

5. Jolly SS, Amlani S, Hamon M, Yusuf S, Mehta SR. Radial versus femoral access for coronary angiography or intervention and the impact on major bleeding and ischemic events: a systematic review and meta-analysis of randomized trials. Am Heart J 2009; 157: 132-40.

6. Di Mario C, Viceconte N. Radial angioplasty: worthy RIVAL, not undisputed winner. Lancet 2011; 377: 1381-3.

7. Vorobcsuk A, Konyi A, Aradi D, et al. Transradial versus transfemoral percutaneous coronary intervention in acute myocardial infarction. Systematic overview and meta-analysis. Am Heart J 2009; 158: 814-21.

8. Singh PP, Singh M, Khosla N, et al. Safety and efficacy of transradial versus transfemoral percutaneous coronary intervention in acute myocardial infarction: a meta-analysis of randomized trials. Coron Artery Dis 2012; 23: 284-93.

9. Joyal D, Bertrand OF, Rinfret S, Shimony A, Eisenberg MJ. Meta-analysis of ten trials on the effectiveness of the radial versus the femoral approach in primary percutaneous coronary intervention. Am J Cardiol 2012; 109: 813-8.

10. Mamas MA, Ratib K, Routledge $\mathrm{H}$, et al. Influence of access site selection on PCl-related adverse events in patients with STEMI: meta-analysis of randomised controlled trials. Heart 2012; 98: 303-11.

11. Jang JS, Jin HY, Seo JS, et al. Transradial versus transfemoral approach for primary percutaneous coronary intervention in patients with acute myocardial infarction: a systematic review and meta-analysis. Eurointervention 2012; 8: 501-10.

12. Moher D, Liberati A, Tetzlaff J, Altman DG. Preferred reporting items for systematic reviews and meta-analy- 
ses: the PRISMA statement. Ann Intern Med 2009; 151: 264-9.

13. Higgins JPT, Green S. Cochrane handbook for systematic reviews of interventions. Wiley-Blackwell 2009.

14. Saito S, Tanaka S, Hiroe Y, et al. Comparative study on transradial approach vs. transfemoral approach in primary stent implantation for patients with acute myocardial infarction: results of the test for myocardial infarction by prospective unicenter randomization for access sites (TEMPURA) trial. Catheter Cardiovasc Interv 2003; 59: 26-33.

15. Cantor WJ, Puley G, Natarajan MK, et al. Radial versus femoral access for emergent percutaneous coronary intervention with adjunct glycoprotein Ilb/IIla inhibition in acute myocardial infarction: the RADIAL-AMI pilot randomized trial. Am Heart J 2005; 150: 543-9.

16. Chodor P, Kurek T, Kowalczuk A, et al. Radial vs femoral approach with StarClose clip placement for primary percutaneous coronary intervention in patients with ST-elevation myocardial infarction. RADIAMI II: a prospective, randomised, single centre trial. Kardiol Pol 2011; 69: 763-71.

17. Chodor P, Krupa H, Kurek T, et al. RADIal versus femoral approach for percutaneous coronary interventions in patients with Acute Myocardial Infarction (RADIAMI): a prospective, randomized, single-center clinical trial. Cardiol J 2009; 16: 332-40.

18. Yan ZX, Zhou YJ, Zhao YX, et al. Safety and feasibility of transradial approach for primary percutaneous coronary intervention in elderly patients with acute myocardial infarction. Chin Med J (Engl) 2008; 121: 782-6.

19. Brasselet C, Tassan S, Nazeyrollas P, Hamon M, Metz D. Randomised comparison of femoral versus radial approach for percutaneous coronary intervention using abciximab in acute myocardial infarction: results of the FARMI trial. Heart 2007; 93: 1556-61.

20. Hou L, Wei YD, Li WM, Xu YW. Comparative study on transradial versus transfemoral approach for primary percutaneous coronary intervention in Chinese patients with acute myocardial infarction. Saudi Med J 2010; 31: 158-62.

21. Mehta SR, Jolly SS, Cairns J, et al. Effects of radial versus femoral artery access in patients with acute coronary syndromes with or without ST-segment eevation. J Am Coll Cardiol 2012; 60: 2490-9.

22. Romagnoli E, Biondi-Zoccai G, Sciahbasi A, et al. Radial versus femoral randomized investigation in ST-segment elevation acute coronary syndrome: the RIFLE-STEACS (Radial Versus Femoral Randomized Investigation in ST-Elevation Acute Coronary Syndrome) study. J Am Coll Cardiol 2012; 60: 2481-9.

23. Gan L, Li Q, Liu R. Effectiveness and feasibility of transradial approaches for primary percutaneous coronary intervention in patients with acute myocardial infarction. J Nanjing Med Univ 2009; 23: 270-4.

24. Vazquez-Rodriguez JM, Baz-Alonso J, Calvino-Santos R, et al. Radial vs. femoral arterial access in emergent coronary interventions for acute myocardial infarction with ST segment elevation. J Am Coll Cardiol 2007; 49 (9, Suppl 2): 12B.

25. Bertrand OF, Rao SV, Pancholy S, et al. Transradial approach for coronary angiography and interventions: results of the first international transradial practice survey. JACC Cardiovasc Interv 2010; 3: 1022-31.

26. Amoroso G, Laarman GJ, Kiemeneij F. Overview of the transradial approach in percutaneous coronary intervention. J Cardiovasc Med (Hagerstown) 2007; 8: 230-7.
27. Bertrand OF, Belisle P, Joyal D, et al. Comparison of transradial and femoral approaches for percutaneous coronary interventions: a systematic review and hierarchical Bayesian meta-analysis. Am Heart J 2012; 163: 632-48.

28. Chase AJ, Fretz EB, Warburton WP, et al. Association of the arterial access site at angioplasty with transfusion and mortality: the M.O.R.T.A.L study (Mortality benefit Of Reduced Transfusion after percutaneous coronary intervention via the Arm or Leg). Heart 2008; 94: 1019-25.

29. Mehta SR, Jolly SS, Cairns J, et al. Effects of radial versus femoral artery access in patients with acute coronary syndromes with or without ST-segment elevation. J Am Coll Cardiol 2012; 60: 2490-9.

30. Jolly SS, Yusuf S, Cairns J, et al. Radial versus femoral access for coronary angiography and intervention in patients with acute coronary syndromes (RIVAL): a randomised, parallel group, multicentre trial. Lancet 2011; 377: 1409-20.

31. Steg PG, James SK, Atar D, et al. ESC Guidelines for the management of acute myocardial infarction in patients presenting with ST-segment elevation: The Task Force on the management of ST-segment elevation acute myocardial infarction of the European Society of Cardiology (ESC). Eur Heart J 2012; 33: 2569-619. 